\title{
Sen-itiroh Hakomori and tumor-associated glycosphingolipids: an astoundingly productive decade, 1980-1990
}

\author{
Edward Nudelman ${ }^{1}$
}

Received: 20 September 2021 / Accepted: 4 October 2021 / Published online: 26 November 2021

(c) The Author(s), under exclusive licence to Springer Science+Business Media, LLC, part of Springer Nature 2021

Sen-itiroh Hakomori, or Dr. H, as I called him, was both a mentor and friend, a brilliant scientist with whom I had the honor and benefit of working, both professionally and later collegially, for nearly fifty years. In later years, we managed to stay in close contact, and I'd often visit him in his laboratory on Capitol Hill, near downtown Seattle, where he headed up a lab at the Pacific Northwest Research Foundation, working virtually right up until his passing, in 2020 at the age of 91 . We coauthored 55 papers, most of them occurring in the decade of 1980-1990, and I am fortunate to have had the opportunity of knowing Dr. H personally on many levels. From laboratory bench-side enthusiast and unswerving scientific leader, to an informal host of events and parties, Dr. $\mathrm{H}$ always impressed with his uncanny ability to seamlessly compartmentalize science and his private life. Those lucky enough to see him in action over many years, came to appreciate both faculties at work, an individual with unparalleled scientific ability, in addition to possessing an appreciation for all things beautiful and serene: his family, friends, the natural world around him, and, of course, his glycolipids.

In the Spring of 1975 , I was a Chemistry major at University of Washington (UW), Seattle, needing to beef up my resume in anticipation of submitting my medical school application. A job opportunity at the newly opened Fred Hutchinson Cancer Research Center ("Fred Hutch") opened up, and I was lucky enough to obtain an interview the next day with Dr. Hakomori. Querying me on my lab experience, Dr. H probed my knowledge of cancer biology, as well as showing interest in my declared hobbies of guitar and hiking. At one point, near the end of the interview, he looked up at me squarely,

Edward Nudelman

enudelman@msn.com

111346 19th Ave. N.E, Seattle, WA, USA and asked: "I can see you're an intelligent individual with lots of promise, but can you work long hours in the lab?" I think I gave him a fairly standard reply, but his focus on dedication and love for his work have always stayed with me.

When Dr. $\mathrm{H}$ engaged in science, he was extremely focused, and he was not easily distracted away from it. He made this clear to me often, sometimes chiding me for making a mistake, or not following his advice to the letter, but concluding with, "You'll do better next time!" Yet, behind the stern face during long laboratory hours, he nevertheless constantly provided his students and colleagues an open environment with creative exchange of ideas. Whenever it came time to say farewell to a lab member, he'd treat the entire lab to a fine lunch at a local Japanese restaurant, and open up delightfully in a winsome manner, and always presenting the leaving lab member with an illustrated book of the Pacific Northwest. This upbeat, positive attitude never changed, as long as I knew him. Whenever he'd introduce me to friends or colleagues, he'd say, "This is Ed Nudelman, my right hand." It always left me with a lump in my throat, and a good deal of pride and appreciation for a man who taught me so much in so many different areas of life.

The 1980's in the Hakomori Lab were bustling years, focusing on the isolation and purification of tumor-associated glycosphingolipids (GSLs). A collaborative team was formed within the matrix of investigators, to which Dr. $\mathrm{H}$ was a strong organizing force. At its peak, the team comprised over ten scientists and many lab techs, and produced an astonishing 290 papers in the decade of 1980-1990, more than a third of Hakomori's lifetime achievement (which totaled in excess of 700 papers). Several important technological advances were brought into focus and practice during this time. Large-scale organic extraction techniques and innovative protocols involving new organic solvent compositions facilitated maximal recovery of ever longer-chained and more complex glycolipids, peaking at 
nearly 30 monosaccharides with a linear polylactosamine core on a glycolipid isolated from placenta.

Under Dr. Hakomori's watchful eye, we processed huge amounts of organic tissue extracts, applying the newly developed high performance liquid chromatography (HPLC) platform. As well, we performed exquisite separation of glycolipids with high performance thin layer chromatography (HPTLC), often in two-dimensions as native species, and also acetylated glycolipids to improve homogeneity. This provided ever-increasing resolution of comigrating species into additional novel molecular species. Importantly, the HPTLC plates allowed for direct immunostaining, as introduced early on by John Magnani. By utilizing the emerging monoclonal antibodies produced in our lab, and the further dissection of immunoreactive species, we were able to characterize many novel GSL via structural methylation analysis, mass spectrometry (MS) and nuclear magnetic resonance (NMR) spectroscopy. Importantly, a number of these novel tumor-associated compounds went into our monoclonal antibody development program, yielding many interesting MoAbs still used today as probes, in histological assays, and even a commercialized Japanese cancer diagnostic test.

My first project in the lab, back in 1976, was to assist the young professor Bill (William) Carter with his groundbreaking work on the discovery of fibronectin, which emanated directly from the Hakomori lab. I quickly learned that my first responsibility was to help isolate and purify the highly toxic ricin lectin from castor beans, used for column chromatography. I was given a brief introduction by Dr. H, then Bill gave me a primer course on the risks and perils of ricin poisoning, after which I donned goggles and gloves and dove in. The experience was burned in my memory and induced in me a rigorous tenacity for following protocols and methods strictly when told. Years later, this experience developed into a poem, slightly stretching the facts, which the reader may find amusing:

\section{My First Project}

I cut my teeth in the lab purifying the world's most toxic poison. Not really poison, per se, which might imply intentthis substance had no purpose disclosed to me, except that it be synthesized, purified, and handed over to the boss. Double-glove and double-mask, he said, and double-wash afterwardsin fact, better close your eyes during pipetting and transferring, don't inhale when pouring and don't breathe in, when collecting. To be safe, shower at home, purge with castor oil, burn your clothes, and put on sackcloth and ashes.

It was a period in my life I look back on romantically, with a tinge of the macabre and an unhealthy dose of gothic.

The expansive space on the fourth floor of Fred Hutch, in the department officially named Biochemical Oncology, overlooked "Pill Hill," a nickname reflecting the Capitol Hill location of the neighborhood and its demographic, which includes numerous major hospitals serving the city of Seattle. Of course, the outlook from the main lab area, without windows, was rather limited. However, Dr. $\mathrm{H}$ once remarked that his first year here was a bit less productive, as he was too often distracted by wonderful peeks at the beautiful Mt. Rainier from his little office window, "a bit obstructed, but a nice view when standing." 
The Hakomori labs were impressive, comprising over half of the space on the entire floor, which was immense. The other half was occupied by such luminaries as Robert Nowinski, who went on to found Seattle's first biotech company, Genetic Systems, and the famed Hellströms, Robert Erik and Ingegerd, who pioneered some of the earliest research on cancer immunology and were one of the first to produce monoclonal antibodies directed at cancer antigens. My "spot" was located opposite that of Kiyohiro Watanabe, a quiet, yet remarkably astute glycolipid scientist whose 12 -foot lab bench was completely covered with glass columns eluting fractions of organic solvent into hundreds of test tubes.

Watanabe had earlier joined the original lab in the 1970 's, at the University of Washington, prior to the move to Fred Hutch, whose members (Bader Siddiqui, Roger Laine, Carl Gahmberg, Klaus Stellner, and others) formed the nucleus for great strides and advances, which we were grateful to inherit. During that period, Dr. H's lab made quantum leaps in the isolation of GSL's, with large-scale extraction techniques of red blood cells, roto-evaporation of organic solvents, purification of lipid classes using bulk acetylation to remove the phospholipid fraction and subsequent silicic acid columns for gradient separation. But the new lab at Fred Hutch offered space to further advance experimental capabilities, procure state-of-the-art instrumentation, and hire fresh minds. This increased the size and quality of the team, with a unique confluence of like-minded staff and postdocs which Dr. H brought together in a very short period of time. People came from all over the world with different backgrounds in biochemistry, immunology, cell biology, histopathology, including a plethora of postdocs, established scientists, clinical doctors and dentists.

Dr. H's office was cluttered, and we seldom chatted in there; he had an adjacent smaller room where we'd have long data downloads and discussions. I looked forward to these informal meetings, and he always made himself available, without reservation. One instance stands out as an early encouragement, if not challenge, to me personally. We had been discussing my suggestion that we find ways to obtain larger amounts of cancer tissue. These were the days before well-organized national tissue procurement agencies, and he suggested I approach Swedish Hospital, across the street, to see if we could obtain newly recovered cancer tissue. He knew the director of Pathology there, and we contacted him together that very day. In a few days, I had secured an appointment to discuss a collaboration. However, when I arrived for the meeting, the director was not available, and I was referred to his technician, who was the diener (a term I had never heard previously) of the hospital morgue. I was given a mask and a chair in the corner, while he worked away, discussing a plan of action. Soon, we were obtaining large samples of liver and kidney tumors, as well as lung and brain. As the collaboration progressed, we were provided with both solid tumors as well as in some cases adjacent normal tissues, which allowed us to compare normal and tumor-associated glycolipid species.

During this time, I was also managing the huge erythrocyte membrane program in our lab-coming in very early to collect blood from hundreds of outdated unit bags, and pooling them into several five-gallon buckets for lysing. Huge preparative blood centrifuges were working literally day and night to separate out membranes, which were eventually collected, frozen in batches and stored in freezers. Glycolipid fractions purified and fractionated into pools by HPLC, served as invaluable sources for mining blood group glycolipids and supplying the lab with GSL standards.

Reiji Kannagi joined our lab in 1981, and was instrumental in moving forward novel purification protocols for recovering complex, neutral glycolipids, where simple classical methods were not sufficient to separate co-migrating species. I worked closely with him on many projects, most notably: dissecting the SSEA-1 epitope [1], defining the GD3 melanoma-associated ganglioside [2], describing a glycolipid antigen (globotriaosylceramide) associated with Burkitt's Lymphoma [3], assisting Dr. Henrik Clausen in characterizing $\mathrm{A}^{\mathrm{x}}$ glycolipid [4], and finally, isolating and purifying extended polyfucosyl $\mathrm{Le}^{\mathrm{x}}$-containing glycolipids in adenocarcinoma, thus elucidating for the first time a difucosylated and trifucosylated $\mathrm{Le}^{\mathrm{x}}$ species (lactofucopentaose(III)ceramide) [5]. Importantly, we later discovered that MoAbs could be generated which recognized the internal $\mathrm{Le}^{\mathrm{x}}$ moieties.

Yasuo Fukushi joined our group in 1984, and during the next five years made major contributions toward the production of tumor-associated MoAbs, in addition to describing cellular and histological localization of antigens recognized by these antibodies. Fukushi showed through MoAb histological survey that novel fucolipids accumulating in adenocarcinoma exhibited extended $\mathrm{Le}^{\mathrm{x}}$ epitopes, as well as in human embryonic tissues [6]. As part of our collaborative studies on extended sialyl-Le ${ }^{\mathrm{x}}$, Fukushi produced an elegant MoAb, FH6, showing high affinity to sialyl-Le ${ }^{\mathrm{x}}$ moieties carried not only on short chain backbones, but also longer chain species with multiple internal fucosylation sites [7]. He further compared its occurrence, localization, and distribution in normal and cancer tissues [8], as well as presenting data confirming sialosylated Lewis ${ }^{\mathrm{x}}$ as a tumor-associated antigen [9]. To fully characterize FH6 sub-specificity, it was necessary to isolate and purify multiple analogs of sialyl-Le ${ }^{\mathrm{x}}$ from adenocarcinoma. To this end, I was able to isolate and purify a novel fucoganglioside, $6 \mathrm{~B}$, which is accumulated in colonic adenocarcinoma, but absent in normal colonic 
mucosa. We used this purified compound, specifically to produce (FH6), secreting an IgM MoAb, directed to this glycolipid.

Among the other projects on which Fukushi and I worked together were my isolation of a tumor-associated disialosyl species containing di-Le ${ }^{\mathrm{a}}$ epitopes and defined by the FH9 antibody [10], as well as his elegant immunohistochemical comparisons of $\mathrm{Le}^{\mathrm{a}}$, and both mono- and disialosyl- $\mathrm{Le}^{\mathrm{a}}$ antigens in human colorectal and pancreatic tissues [11].

An early collaboration that took advantage of the expertise in our lab is worth noting, as it also led to a life-long friendship between me and a young dentist, who came to us from the Erik Dabelsteen lab in Copenhagen. Dr. Clausen proved to be an astute and competent research scientist whose lab today in Copenhagen is among the world leaders in glycoconjugate research. However, in early 1983, Dr. Henrik Clausen appeared in the lab as a neophyte, introducing himself to me, and then asking if there was a MacDonald's close by. We spent the next hour discussing science and hamburgers, which soon became our daily habit for lunch. Eager to understand the molecular basis in $\mathrm{ABO}$ blood group carbohydrate biochemistry, Henrik jumped right in. In a collaborative study with Dabelsteen, he had showed how sequential changes in glycosylation occur during normal cell differentiation in squamous epithelia and how incomplete synthesis with accumulation of precursors characterize the early stages of malignancy. Henrik and I, along with Steve Levery, collaborated on a long series of studies to discover new blood group GSLs in the ABO system, including the globoseries blood group A glycolipid $\left(\mathrm{A}^{\mathrm{x}}\right)$ [4], and the repetitive A glycolipids (type 3 chain) defined by blood group A1-specific monoclonal antibodies [12]. Later, Dr. Thayer White joined the lab, and participated in the isolation of blood group A enzyme, which ultimately led to the cloning and characterization of the blood group $\mathrm{ABO}$ genes, in 1990 [13].

Regarding analytical studies, we were fortunate to be able to purchase in the early 1980's a state-of-the-art mass spectrometer. Mark Powell (in our lab from 1977-1981), developed glycolipid sample presentation and derivatization necessary for structural verification, including enzymatic degradations and methylation analysis, and applied MS to provide hitherto unprecedented insights into the structure of the glycolipids isolated. The excellence in GSL structural elucidation was further advanced when Steven Levery joined our lab (1981), and helped the Hakomori lab reach a high-water mark of excellence and academic output during the next 15 years. He coauthored some 71 papers emanating from the Hakomori lab, and he brought into the lab new and improved mass spectrometric hardware and software, a state-of-the-art NMR, and perfected new techniques advancing the careers of others in the lab. In 1986, Levery, Clausen, and myself, led by Dr. H, founded the non-for-profit research center, The Biomembrane Institute (BMI), at the waterfront in the Seattle harbor, right next to the iconic Post Intelligencer Building. The BMI was funded by generous support from the Japanese Otsuka Pharmaceutical company, and was actively producing high-level cancer research from 1986-1996, thus greatly accelerating Dr. H's basic research and translational science.

The search for a target for the stage-specific embryonic antigen (SSEA-1) first characterized by Barbara Knowles, represents a fascinating story involving elegant application of analytical and preparative separation methods in our lab. Hakomori's early collaboration with Knowles allowed us to obtain the SSEA-1 MoAb for the purpose of examining glycolipids from human erythrocytes and cancer cells and tissue. An early paper from our lab described reactivity with a branched GSL [14], but this was later clarified in a second paper from our lab, in 1981, utilizing improved purification techniques involving acetylation and preparative recovery on HPTLC, and we were finally able to show that the SSEA-1 epitope was directed against the terminal Lewis ${ }^{\mathrm{x}}$ epitope [15]. Novel extraction techniques, using more polar solvents (combinations of isopropanol/hexane/water with much higher water content) further enabled us to isolate extended terminal $\mathrm{Le}^{\mathrm{x}}$ species glycolipids on increasingly longer polylactosaminyl backbones. These were later purified, and some were recognized by the SSEA-1 MoAb, while other MoAbs recognizing internal $\mathrm{Le}^{\mathrm{x}}$ epitopes were later developed in our lab.

One of the high points for me personally was to participate in a multi-disciplinary project culminating in two landmark publications $(1990,1991)$ between our lab and Jim Paulson's celebrated lab (along with Laurie Phillips), where we identified the glycolipid ligand for both ELAM-1 [16] and CD62 [17] adhesion molecules as Sialyl-Le ${ }^{\mathrm{x}}$ terminated GSLs. We showed that T- and B-lymphocytes in resting state lack its expression and are induced to strongly express Sialyl-Le ${ }^{\mathrm{x}}$ upon activation. Importantly, whereas the short chained Sialyl-Le ${ }^{\mathrm{x}}$ GSL showed similar binding capacity for the two selectins, a longer sialylated polyfucosylated $\mathrm{Le}^{\mathrm{x}}$ isolated and characterized in our lab had much higher-affinity binding to the P-Selectin, punctuating the remarkable sensitivity of these receptors to internal Lewis ${ }^{\mathrm{x}}$ epitopes.

On the basis of the advances in technological capabilities described above, we established a "library" of mixed cancer tissue-derived GSLs, both acidic (gangliosides) and neutral, with a huge range of molecular weights, from very simple to highly complex, as confirmed by HPLC and HPTLC. Some of the polar neutral GSLs were interesting because they reacted specifically with a MoAb (ACFH-18) that we had produced from human gastric cancer cell line MKN75. I used ACFH-18 MoAb in preparative immune overlays on HPTLC to isolate and purify a very slow-migrating, polar GSL species from this library and we demonstrated, in 1988, 
that the antibody reacted with an internal $\mathrm{Le}^{\mathrm{x}}$ monofucosylated (1-3) linkage on a 10-sugar backbone, regardless of terminal sialylation [18].

Later that year, Dr. H said he had a surprise for me, and led me out of the lab and down the long hall, past the restrooms. I knew where he was going: to the hallowed lab of the Hellströms (Karl Erik and Ingegerd), well-known names in the Seattle scientific community because of their pioneering work on cancer and immunology. The Hellströms had obtained an IgM MoAb that reacted with a surface antigen expressed on most human melanomas, and I was able to determine that the antibody reacted specifically with a disialosyl ganglioside, GD3, which was purified from adenocarcinoma tissues from the Swedish Hospital, across the street! [2]

The isolation and purification of complex, extended polyfucosylated $\mathrm{Le}^{\mathrm{y}}$ epitopes on a large octaosylceramide backbone, from my point of view, was a "proof of principle" for the elegant analytical techniques being perfected in our lab. This process involved huge amounts of starting tissue, and lengthy crude sub-fractionations of lipids, and culminated in fine separation on HPTLC plates using various MoAb overlays to detect active fractions. The final result was recovery of a homogenous trifucosylated $\mathrm{Le}^{\mathrm{y}} \mathrm{GSL}$, and the development of MoAbs indicating recognition of the internal epitope, and a putative probe as a tumor-associated cancer target [19] [20].

In early 1989, during the course of surveying certain cationic lipids in the human brain, we happened on to a very interesting process recovering large amounts of positively charged GSL's. I had recently learned to apply cation exchange chromatography to the methods of polar GSL isolation, and to my great surprise, we recovered a completely novel, bioactive GSL, containing a plasmal (fatty aldehyde) conjugated to psychosine with a cyclic acetal linkage. Accumulation of psychosine in the brain is not observed due to its toxicity, so the naturally occurring derivate seemed to represent a metabolic detoxification step. This GSL, which we termed "plasmalopsychosine," inhibited protein kinase $\mathrm{C}$ (PKC) activity and was not cytotoxic to cells, and thus might provide a crucial step in regulation of PKC, or other kinases [21].

\section{A few personal reflections}

Dr. H's stature in science arose from the combination of his solid early training in biochemistry as well as his commitment and drive to focus on cancer and glycoconjugate research. His flexibility in devising and proposing new methods and creative avenues of inquiry stemmed from a careful consideration of the interests and capabilites of his lab personnel. He recruited individuals from all over the world, each with varying personalities, bringing with them a wide variety of skills dovetailing perfectly with the whole.

Regarding data analysis, he most often let the results speak for themselves, directing the research based on viable hypotheses which were verified with promising results. I observed this over and over in our weekly lab meetings. If a particular project seemed to be dead-ending, he'd suggest a new project to pursue, side-by-side. In the long run, this approach was highly effective and productive, yielding an astonishing $740+$ papers in his career! But it should be quickly added, Dr. $\mathrm{H}$ was also a very humble man, with a quick wit often aimed at his own shortcomings. His eldest son related to me, "I asked my father what he did at work, and he quickly replied, 'Just eat and drink, and visit the restroom often."

Lab work focusing on isolation and preparation of chemical species can be a risky proposition. One incident I'll never forget occurred while I was extracting a large amount of tumor tissue in gallons of organic solvent in an industrial size Waring blender. While Dr. H and I were discussing how long to let it go, the blender suddenly bumped, making an uncontrolled grinding noise. The lid suddenly flew off, as my hand went obliquely across the moving blade; and some of the contents splashed up in my face. I received a rather nasty gash on my thumb and index finger, as well some chloroform/methanol in my face. All ended well, with a few stitches and lots of tension, but it was Dr. $\mathrm{H}$ and his coolness under fire that saved the day. He immediately led me over to the sink to wash out my eyes, then escorted me across the street to the Swedish Hospital ER, where he sat with me for hours while they stitched me up, talking about his garden and his beloved turtle.

Regarding said turtle, Dr. H's eldest son once related the story of its origin. His son had found a tiny turtle crawling around in the neighborhood, and brought it home, insisting to his father to let him keep it, and promised to take good care of it. So, Dr. H did let him keep it, without realizing, until much later, that it was slowly growing into a large tortoise. But, Dr. $\mathrm{H}$ came to cherish that turtle, and it would always be his great treat to show it off during dinners at his house. He said that he believed the turtle brought him good luck; but on occasion it would crawl away and disappear, and he'd become frantic. The entire family then had to search for it, and once found, he'd rejoice and say, "Never again!".

Dr. H loved to travel, not only to scientific conferences, but also privately, with his family. He particularly loved the Amalfi coast, Genoa, and Italy in general. He collected silver spoons everywhere he went, and the family now has a large collection from many of the countries he visited. One personal memory of traveling with Dr. $\mathrm{H}$ stands out as a splendid example of his light-hearted nature and fondness of having a good time. We were 
invited to attend the IXth International Symposium on Glycoconjugates in Lille, France, July 6-11, 1987. Shortly after giving his scheduled talk, Dr. H suggested that we all dine at some very special place-and could we handle the reservations? One of us (the name will not be divulged) suggested a "modest Michelin three-star restaurant" (as a joke), but Dr. H said, "sure, let's do it!" We tried to talk him out of it, but he was adamant, and insisted he'd treat us all.

It turned out to be one of the most memorable meals any of us have ever had. After the waiter had pronounced the 10-course set menu in perfect French, Dr. H replied to the waiter, "All of my associates will probably have the pre-set menu, however I would just like a little fish and some white rice!" Given that Dr. H suffered severely from jetlag, he dosed off after the first dish, and only woke up for a moment, every time the waiter loudly announced the next dish. None of us had the nerve to wake him, but we did order another bottle or two of Bordeaux, waiting for him. The critical point was when the check was produced, and he was still fast asleep; after what seemed hours, he finally woke up, and took the bill. We all imagined he'd probably need to take out a loan to finance that meal. On the way home in a cab he kept remarking how wonderful the wine was, and that it must have been very expensive-we all snickered in the back seat. To this day, when I pour a glass of really fine red wine, I fondly think of Dr. $\mathrm{H}$ and Lille and the wonderful colleagues he brought together.

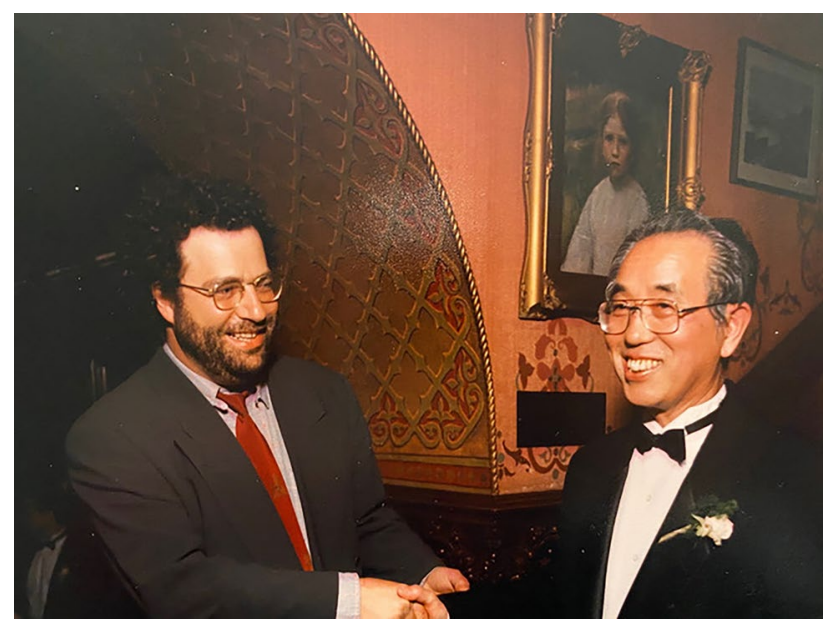

Ed Nudelman congratulating Dr. Hakomori on the occasion of his daughter's wedding, taken at the historic Stimson-Green Mansion, in Seattle, 1993.

\section{References}

1. Kannagi, R., Nudelman, E., Levery, S.B., Hakomori, S.: A series of human erythrocyte glycosphingolipids reacting to the monoclonal antibody directed to a developmentally regulated antigen, SSEA-1. J Biol Chem 257, 14865-14874 (1982)

2. Nudelman, E., Hakomori, S., Kannagi, R., Levery, S., Yeh, M.-Y., Hellstrom, K.E., Hellstrom, I.: Characterization of a human melanoma-associated ganglioside antigen defined by a monoclonal antibody, 4.2. J Biol Chem 257, 12752-12756 (1982)

3. Nudelman, E., Kannagi, R., Hakomori, S., Parsons, M., Lipinski, M., Wiels, J., Fellous, M., Tursz, T.: A glycolipid antigen associated with Burkitt lymphoma defined by a monoclonal antiody. Science 220, 509-511 (1983)

4. Clausen, H., Watanabe, K., Kannagi, R., Levery, S.B., Nudelman, E., Arao-Tomono, Y., Hakomori, S.: Blood group A glycolipid (Ax) with globo-series structure which is specific for blood group A1 erythrocytes: One of the chemical bases for A1 and A2 distinction. Biochem Biophys Res Comm 124, 523-529 (1984)

5. Hakomori, S., Nudelman, E., Levery, S.B., Kannagi, R.: Novel fucolipids accumulating in human adenocarcinoma: I. Glycolipids with di- or trifucosylated type 2 chain. J Biol Chem 259, 46724680 (1984)

6. Fukushi, Y., Hakomori, S., Shepard, T.: Localization and alteration of mono-, di-, and trifucosyl $\square 1 \rightarrow 3$ type 2 chain structures during human embryogenesis and in human cancer. J Exp Med 159, 506-520 (1984)

7. Fukushi, Y., Nudelman, E., Levery, S.B., Hakomori, S., Rauvala, H.: Novel fucolipids accumulating in human cancer. III. A hybridoma antibody (FH6) defining a human cancer-associated difucoganglioside (VI3NeuAcV3III3Fuc2nLc6). J Biol Chem 259, 10511-10517 (1984)

8. Fukushi, Y., Kannagi, R., Hakomori, S., Shepard, T., Kulander, B.G., Singer, J.W.: Localization and distribution of difucoganglioside (VI3NeuAcV3III3Fuc2nLc6) in normal and tumor tissues defined by its monoclonal antibody FH6. Cancer Res 45, 3711-3717 (1985)

9. Fukushima, K., Hirota, M., Terasaki, P.I., Wakisaka, A., Togashi, H., Chia, D., Suyama, N., Fukushi, Y., Nudelman, E., Hakomori, S.: Characterization of sialosylated Lewis ${ }^{\mathrm{x}}$ as a new tumor-associated antigen. Cancer Res 44, 5279-5285 (1984)

10. Fukushi, Y., Nudelman, E., Levery, S.B., Higuchi, T., Hakomori, S.: A novel disialoganglioside (IV3NeuAcIII6NeuAcLc4) of human adenocarcinoma, and the monoclonal antibody (FH9) defining this disialosyl structure. Biochemistry 25, 2859-2866 (1986)

11. Nudelman, E., Fukushi, Y., Levery, S.B., Higuchi, T., Hakomori, S.: Novel fucolipids of human adenocarcinoma: Disialosyl Lea antigen (III4FucIII6NeuAcIV3NeuAcLc4) of human colonic adenocarcinoma and the monoclonal antibody (FH7) defining this structure. J Biol Chem 261, 5487-5495 (1986)

12. Clausen, H., Levery, S.B., Nudelman, E., Tsuchiya, S., Hakomori, S.: Repetitive A epitope (type 3 chain A) defined by blood group A1-specific monoclonal antibody TH-1: Chemical basis of qualitative A1 and A2 distinction. Proc Natl Acad Sci USA 82, 1199-1203 (1985)

13. Clausen, H., White, T., Takio, K., Titani, K., Stroud, M., Holmes, E., Karkov, J., Thim, L., Hakomori, S.: Isolation to homogeneity and partial characterization of a histoblood group A defined Fuc $\square 1 \rightarrow 2$ Gal $\square 1 \rightarrow 3-N$ - acetylgalactosaminyltransferase from human lung tissue. J Biol Chem 265, 1139-1145 (1990) 
14. Nudelman, E., Hakomori, S., Knowles, B.B., Solter, D., Nowinski, R.C., Tam, M.R., Young, W.W., Jr.: Monoclonal antibody directed to the stage-specific embryonic antigen (SSEA-1) reacts with a branched glycosphingolipid similar in structure to Ii antigen. Biochem Biophys Res Comm 97, 443-451 (1980)

15. Hakomori, S., Nudelman, E., Levery, S., Solter, D., Knowles, B.B.: The hapten structure of a developmentally regulated glycolipid antigen (SSEA-1) isolated from human erythrocytes and adenocarcinoma: A preliminary note. Biochem Biophys Res Comm 100, 1578-1586 (1981)

16. Phillips, M.L., Nudelman, E., Gaeta, F.C.A., Perez, M., Singhal, A.K., Hakomori, S., Paulson, J.C.: ELAM-1 mediates cell adhesion by recognition of a carbohydrate ligand, sialyl-Lex. Science 250, 1130-1132 (1990)

17. Polley, M.J., Phillips, M.L., Wayner, E., Nudelman, E., Singhal, A.K., Hakomori, S., Paulson, J.C.: CD62 and endothelial cellleukocyte adhesion molecule 1 (ELAM-1) recognize the same carbohydrate ligand, sialyl-Lewisx. Proc Natl Acad Sci USA 88, 6224-6228 (1991)

18. Nudelman, E.D., Levery, S.B., Stroud, M.R., Salyan, M.E.K., Abe, K., Hakomori, S.: A novel tumor- associated, developmentally regulated glycolipid antigen defined by monoclonal antibody ACFH-18. J Biol Chem 263, 13942-13951 (1988)
19. Nudelman, E., Levery, S.B., Kaizu, T., Hakomori, S.: Novel fucolipids of human adenocarcinoma: Characterization of the major Ley antigen of human adenocarcinoma as trifucosylnonaosyl Ley glycolipid (III3FucV3FucVI2FucnLc6). J Biol Chem 261, 11247-11253 (1986)

20. Kaizu, T., Levery, S.B., Nudelman, E., Stenkamp, R.E., Hakomori, S.: Novel fucolipids of human adenocarcinoma: Monoclonal antibody specific for trifucosyl Ley (III3FucV3FucVI2FucnLc6) and a possible three-dimensional epitope structure. J Biol Chem 261, 11254-11258 (1986)

21. Nudelman, E.D., Levery, S.B., Igarashi, Y., Hakomori, S.: Plasmalopsychosine, a novel plasmal (fatty aldehyde) conjugate of psychosine with cyclic acetal linkage: Isolation and characterization from human brain white matter. J Biol Chem 267, 11007-11016 (1992)

Publisher's Note Springer Nature remains neutral with regard to jurisdictional claims in published maps and institutional affiliations. 